\title{
Participação de alunos com deficiência física no contexto da escola regular- Revisão de Literatura
}

\section{Participation of students with physical disabilities in mainstream schools- literature review}

\author{
Lívia Santos Lara Ghedini', Marisa Cotta Mancini², \\ Marina de Brito Brandão ${ }^{3}$
}

\begin{abstract}
GHEDINI, L. S. L.; MANCINI, M. C.; BRANDÃO, M. de B. Participação de alunos com deficiência física no contexto da escola regular- Revisão de Literatura. Rev. Ter. Ocup. Univ. São Paulo, v. 21, n. 1, p. 1-9, jan./abr. 2010.
\end{abstract}

RESUMO: A educação inclusiva é uma realidade vigente, que consiste não somente na socialização da criança com deficiência, mas também na criação de oportunidades para que a mesma possa participar dos diversos contextos da escola. Para tanto, é fundamental o preparo dos profissionais envolvidos nesse processo, de forma que a criança receba o suporte necessário e adequado. $\mathrm{O}$ objetivo deste estudo é analisar, através de uma revisão da literatura, evidências disponíveis sobre a participação da criança com deficiência física no contexto da escola regular. Foram realizadas buscas em bases eletrônicas de dados e em revistas de educação. As palavras chaves utilizadas foram: paralisia cerebral ou deficiência física, inclusão escolar, participação escolar e as respectivas traduções destes termos na língua inglesa. Oito artigos foram incluídos no estudo. A síntese da evidência aponta que os principais fatores que contribuíram para a participação da criança com deficiência física no ambiente escolar referiram-se às habilidades motoras, especificamente mobilidade, à comunicação, ao nível de comprometimento motor e à idade. Barreiras que restringiram a participação, como falta de acesso e inadequação do espaço físico das escolas foram identificadas.

DESCRITORES: Deficiência física. Participação escolar. Inclusão escolar.

\footnotetext{
* Trabalho apresentado ao Curso de Especialização do Departamento de Terapia Ocupacional, Escola de Educação Física, Fisioterapia e Terapia Ocupacional (EEFFTO), Universidade Federal de Minas Gerais (UFMG), como requisito parcial para obtenção do título de Especialista em Terapia Ocupacional na área de Desenvolvimento Infantil, Belo Horizonte, MG, novembro de 2009.

1. Terapeuta Ocupacional, especialista em Desenvolvimento Infantil.

2. Profa. Associada do Departamento de Terapia Ocupacional da EEFFTO-UFMG.

3. Profa. Assistente da Faculdade de Ciências da Saúde, Universidade FUMEC, Doutoranda em Ciências da Reabilitação (EEFFTO, UFMG).

Endereço para correspondência: Profa. Dra. Marisa Mancini, Departamento de Terapia Ocupacional, Escola de Educação Física, Fisioterapia e Terapia Ocupacional da Universidade Federal de Minas Gerais. Av. Pres. Antônio Carlos, 6627 Campus - Pampulha - Belo Horizonte-MG- CEP 31.270-901. e-mail: mcmancini@pib.com.br
} 


\section{INTRODUÇÃO}

$\mathrm{A}$ escola possui papel fundamental no processo de desenvolvimento infantil, sendo primeiro ambiente externo ao contexto familiar que recepciona e coloca a criança na esfera das relações sociais (JURDI, 2004). As primeiras experiências vividas no ambiente escolar são essenciais para a construção da relação do indivíduo com os outros, do modo como este se coloca no mundo e frente ao conhecimento e ao ato criativo (ROSA, 1998). Instituições como a escola, segundo Rocha et al. (2001) emergem como espaço em que os indivíduos se organizam de forma a exercer os papéis sociais adequados.

Para a criança com deficiência, a oportunidade de acesso à escolarização é recente, sendo que até pouco tempo, pequena parcela dessa população tinha acesso à salas de aulas (JURDI, 2006). Este acesso restringia-se às escolas de ensino especializado ou às classes especiais, revelando, assim, a relação entre deficiência e ensino especial, em que a condição de deficiente por si só definiria a conveniência e a necessidade desse atendimento especializado. Após a publicação da Declaração de Salamanca em 1994, a proposta da inclusão escolar passou a ser um direito das crianças com deficiência (GOMES; BARBOSA, 2006). No Brasil, em 1996, ficou determinado o direito ao atendimento educacional aos indivíduos com deficiência, preferencialmente na rede regular de ensino (BRASIL, 1996). Como conseqüência desses movimentos, observa-se a crescente inserção de alunos com deficiência no ensino regular (SCHENKER; PARUSH, 2005).

Pelosi (2002) define a escola inclusiva como o ambiente em que todos os alunos são aceitos e educados em salas de aula regular, com oportunidades adequadas às suas necessidades e habilidades. É uma realidade que torna imprescindível o respeito à diversidade de cada criança e a realização de transformações, quando necessárias,para receber e manter o aluno no processo educativo ativo e construtivo (SILVA et al., 2004). Estas transformações referem-se não somente à modificações e adaptações no ambiente, mas também à postura e ações da equipe escolar, no sentido de favorecer a participação da criança nos diversos contextos da escola.

De acordo com a Classificação Internacional de Funcionalidade, Incapacidade e Saúde (CIF), participação refere-se ao envolvimento em situações diárias, incluindo autonomia e controle sobre a própria vida (PERENBOOM; CHORUS, 2003). No âmbito escolar, Coster (1998) relata que participação ocorre na medida em que cada criança é capaz de engajar-se nas atividades de um contexto de referência, que contemple necessidades e metas individuais, de acordo com as expectativas da sociedade.

Estudos que investigaram a participação de crianças com deficiência física no ambiente escolar relataram que a participação destas é mais restrita quando comparada à de crianças sem deficiência (LAW et al., 2007). Segundo Schenker et al. (2006), a literatura existente tem focado na relação entre o nível de participação de crianças e o comprometimento que apresentam relativos à estrutura e função do corpo além dos fatores ambientais que interferem na participação. Tais evidências são importantes para que a complexidade dessa relação possa ser melhor compreendida, o que poderá favorecer o desenvolvimento de estratégias mais específicas pela equipe escolar e equipe de reabilitação , com o intuito de promover a participação dessas crianças no ambiente da escola. Assim, o objetivo desse estudo é analisar, através de revisão de literatura, evidências disponíveis sobre a participação da criança com deficiência física no contexto da escola regular.

\section{METODOLOGIA}

Foram realizadas buscas bibliográficas nas seguintes bases eletrônicas de dados: Lilacs, Medline, Scielo, OTseeker, PEDRO, Ebscohost (Cinahal), British Education Index, e, através do Portal CAPES, as seguintes revistas foram acessadas: Revista Brasileira de Educação, Revista Brasileira de Educação Especial e a Revista da Faculdade de Educação da USP.

As palavras chaves utilizadas foram: paralisia cerebral ou deficiência física, inclusão escolar, participação escolar e cerebral palsy ou physical disabilities, school inclusion e school participation. Para seleção dos artigos, foram seguidos os seguintes critérios de inclusão: artigos com desfecho em participação escolar, publicados no período de 2000 a 2009 cuja amostra contemplasse crianças /adolescentes de seis a 20 anos, com deficiência física, matriculados em escolas regulares. Para a exclusão dos estudos, os critérios foram: estudos de revisão de literatura e bibliografia comentada.

Na totalidade, foram selecionados 13 artigos que cumpriram os critérios acima. Durante a leitura do resumo, porém, foram descartados cinco estudos, pois estes se referiam à percepção de pais e professores com relação à inclusão, sem investigação empírica com documentação da participação dos alunos. Após a leitura seletiva dos resumos, oito artigos foram incluídos no estudo.

\section{RESULTADOS}

As seguintes informações relativas aos estudos foram organizadas na Tabela 1. 
GHEDINI, L. S. L. et al. Participação de alunos com deficiência. Rev. Ter. Ocup. Univ. São Paulo, v. 21, n. 1, p. 1-9, jan./abr. 2010.

Tabela 1 - Resumo das informações referentes a objetivo, metodologia e resultados dos estudos selecionados

\begin{tabular}{|c|c|c|c|c|}
\hline $\begin{array}{l}\text { Informações referentes aos } \\
\text { objetivos, metodologia e } \\
\text { resultados do estudo. } \\
\text { Referência }\end{array}$ & Objetivos & Participantes & Desfechos & Principais resultados \\
\hline $\begin{array}{l}\text { SCHENKER, R.; } \\
\text { COSTER, W. J.; } \\
\text { PARUSH, S. } \\
\text { Participation and activity } \\
\text { performance of students } \\
\text { with cerebral palsy } \\
\text { within the school environ- } \\
\text { ment. } \\
\text { Disabil Rehabil, 2005; } \\
\text { 27(10):539-552. }\end{array}$ & $\begin{array}{l}\text { Medir o nível de } \\
\text { participação e de } \\
\text { desempenho na atividade } \\
\text { de crianças com paralisia } \\
\text { cerebral (PC) que } \\
\text { freqüentam escolas } \\
\text { regulares primárias em } \\
\text { Israel e investigar a } \\
\text { relação entre esses dois } \\
\text { componentes }\end{array}$ & 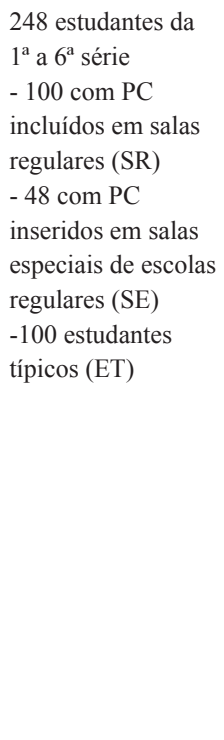 & $\begin{array}{l}\text { - Participação } \\
\text { (SFA - Parte I) } \\
\\
\text { - Desempenho } \\
\text { nas atividades } \\
\text { (SFA - Parte III) }\end{array}$ & $\begin{array}{l}\text { - A participação do grupo ET foi significativamente } \\
\text { superior aos outros grupos e a participação do grupo SR e } \\
\text { SE foi significativamente inferior em todos os domínios, } \\
\text { sendo menor no grupo SE. } \\
\text { - O escore de menor participação entre os estudantes com } \\
\text { PC foi obtido no ambiente de pátio/recreio e o maior } \\
\text { escore de participação foi obtido no lanche. } \\
\text { - Diferenças significativas no desempenho de atividades } \\
\text { físicas, sendo o melhor desempenho o do grupo ET; } \\
\text { ausências de diferenças significativas entre o desempenho } \\
\text { de tarefas físicas entre o grupo SR e SE. } \\
\text { - Diferenças significativas entre os } 3 \text { grupos no } \\
\text { desempenho das atividades cognitivo-comportamentais, } \\
\text { sendo que crianças do grupo ET apresentaram melhor } \\
\text { desempenho e SE pior desempenho. } \\
\text { - Relação positiva entre participação e desempenho físico } \\
\text { e cognitivo-comportamental nos grupos SR e SE. } \\
\text { - Desempenho em tarefas físicas físico foi considerado } \\
\text { principal preditivo de participação nos grupos SR e } \\
\text { SE. Nas crianças do grupo ET, a variável cognitivo- } \\
\text { comportamental foi a de maior predição. }\end{array}$ \\
\hline $\begin{array}{l}\text { SCHENKER, R.; } \\
\text { COSTER, W. J.; } \\
\text { PARUSH, S. } \\
\text { Neuroimpairments, activity } \\
\text { performance, } \\
\text { and participation in } \\
\text { children with cerebral } \\
\text { palsy mainstreamed in } \\
\text { elementary schools } \\
\text { Dev MedChild Neuro } \\
\text { 2005, 47: 808-814 }\end{array}$ & $\begin{array}{l}\text { - Caracterizar as crianças } \\
\text { com PC incluídas em } \\
\text { escolas regulares em } \\
\text { Israel com relação à } \\
\text { idade, sexo, nível de } \\
\text { comprometimento motor } \\
\text { grosso, classificação } \\
\text { e comprometimentos } \\
\text { adicionais } \\
\text {-Analisar diferenças entre } \\
\text { níveis de participação e } \\
\text { desempenho, em tarefas } \\
\text { escolares das crianças em } \\
\text { relação ao tipo deficiência, } \\
\text { nível de comprometimento } \\
\text { motor grosso e } \\
\text { comprometimentos } \\
\text { associados } \\
\text {-Analisar a relação } \\
\text { entre desempenho em } \\
\text { atividades, severidade de } \\
\text { comprometimento motor e } \\
\text { participação das crianças } \\
\text { com PC }\end{array}$ & $\begin{array}{l}148 \text { estudantes com } \\
\text { PC, da } 1^{\mathrm{a}} \text { a } 6^{\mathrm{a}} \text { série } \\
\text { - } 100 \text { incluídos em } \\
\text { salas regulares (SR) } \\
\text { - } 48 \text { inseridos em } \\
\text { salas } \\
\text { especiais de escolas } \\
\text { regulares (SE) }\end{array}$ & $\begin{array}{l}\text { - Participação } \\
\text { (SFA- Parte I) } \\
\text { - Desempenho } \\
\text { nas atividades } \\
\text { (SFA - Parte III) }\end{array}$ & $\begin{array}{l}\text { - Diferenças significativas entre tipo clínico e } \\
\text { participação de crianças SR e SE, bem como no } \\
\text { desempenho de tarefas físicas nos grupos SR e SE e de } \\
\text { tarefas cognitivas no grupo SR, com escores superiores } \\
\text { nestas variáveis nas crianças com hemiplegia espástica, } \\
\text { seguido de alunos com diplegia espástica. Escores } \\
\text { inferiores nos alunos com tetraplegia espástica. } \\
\text {-Diferenças significativas entre a participação de crianças } \\
\text { com PC com comprometimento da fala, no grupo SR, e } \\
\text { na participação das crianças com PC com dificuldade de } \\
\text { aprendizagem, no grupo SE. } \\
\text {-Em ambos os grupos, alunos com GMFCS II } \\
\text { apresentaram desempenho significativamente superior em } \\
\text { relação aos alunos com GMFCS III, nas tarefas físicas e } \\
\text { cognitivo-comportamentais. } \\
\text { - Desempenho em atividades físicas contribuiu para } \\
\text { diferenças na participação entre os grupos com diferentes } \\
\text { tipos de PC e diferentes níveis de comprometimentos. }\end{array}$ \\
\hline
\end{tabular}


GHEDINI, L. S. L. et al. Participação de alunos com deficiência. Rev. Ter. Ocup. Univ. São Paulo, v. 21, n. 1, p. 1-9, jan./abr. 2010.

\begin{tabular}{|c|c|c|c|c|}
\hline $\begin{array}{l}\text { SCHENKER, R.; } \\
\text { COSTER, W. J.; } \\
\text { PARUSH, S. } \\
\text { Personal assistance, } \\
\text { adaptations and } \\
\text { participation in students } \\
\text { with cerebral palsy } \\
\text { mainstreamed in } \\
\text { elementary schools. } \\
\text { Disabil Rehabil, 2006; } \\
\text { 28(17):1061-1069. }\end{array}$ & $\begin{array}{l}\text { - Analisar as diferenças } \\
\text { entre o nível de } \\
\text { participaçãoe assistência } \\
\text { em } \\
\text { tarefas físicas e cognitivo- } \\
\text { comportamentais em } \\
\text { crianças com PC incluídas } \\
\text { em salas regulares (SR) e } \\
\text { das crianças inseridas em } \\
\text { salas especiais(SE) } \\
\text { - Analisar a relação entre } \\
\text { assistência e adaptação } \\
\text { fornecida, bem como } \\
\text { entre participação e } \\
\text { quantidade de assistência } \\
\text { e adaptações para a } \\
\text { realização das tarefas } \\
\text { físicas e cognitivo- } \\
\text { comportamentais }\end{array}$ & $\begin{array}{l}148 \text { estudantes com } \\
\text { PC de } 6,1 \text { anos a } \\
13,6 \text { anos } \\
\text { - } 100 \text { incluídos em } \\
\text { salas regulares (SR) } \\
\text { - } 48 \text { inseridos em } \\
\text { salas especiais (SE) }\end{array}$ & $\begin{array}{l}\text { - Participação } \\
\text { (SFA- Parte I) } \\
\\
\text { - Suporte para o } \\
\text { desempenho nas } \\
\text { tarefas } \\
\text { (assistência e } \\
\text { adaptação) } \\
\text { (SFA- Parte II) }\end{array}$ & $\begin{array}{l}\text { - O grupo SR apresentou participação superior nos seis } \\
\text { ambientes escolares, em relação ao grupo SE. } \\
\text { - Foi oferecida maior assistência e adaptação nas tarefas } \\
\text { fisicas, em ambos os grupos, do que nas tarefas cognitivo- } \\
\text { comportamentais. } \\
\text { - Assistência e adaptação fornecidas ao grupo SE foram } \\
\text { significativamente superiores do que a oferecida ao grupo } \\
\text { SR. } \\
\text {-Em ambos os grupos observa-se maior provisão de } \\
\text { assistência do que de adaptação e maior assistência } \\
\text { fornecida nas tarefas fisicas do que nas tarefas cognitivo- } \\
\text { comportamentais. } \\
\text { - Não houve diferença significativa na participação da } \\
\text { criança após assistência e adaptação fornecidas nas tarefas } \\
\text { físicas, ou adaptação nas tarefas cognitivo-comportamentais, } \\
\text { porém houve diferença na participação em tarefas cognitivo- } \\
\text { comportamentais, quando oferecida assistência. } \\
\text { - A relação entre assistência fornecida nas tarefas físicas e } \\
\text { participação foi mais forte do que a relação entre assistência } \\
\text { fornecida nas tarefas cognitivo-comportamentais e } \\
\text { participação. }\end{array}$ \\
\hline $\begin{array}{l}\text { EGILSON, S.T.; TRAUS- } \\
\text { TADOTTIR, R. } \\
\text { Participation of students } \\
\text { with physical disabilities } \\
\text { in the school environment. } \\
\text { Am J Occup Ther, } 2009 \\
63(3): 264-272 .\end{array}$ & $\begin{array}{l}\text {-Investigar os fatores que } \\
\text { facilitam ou limitam a } \\
\text { participação escolar de } \\
\text { estudantes islandeses com } \\
\text { comprometimento motor } \\
\text { e explorar a relação entre } \\
\text { esses fatores }\end{array}$ & 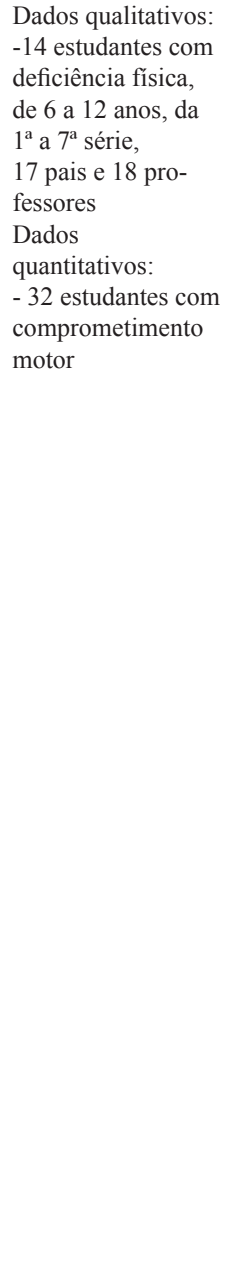 & $\begin{array}{l}\text { Dados } \\
\text { qualitativos: } \\
\text { - Observação } \\
\text { com foco em } \\
\text { participação, } \\
\text { interação com o } \\
\text { grupo de estu- } \\
\text { dantes e com os } \\
\text { adultos } \\
\text {-Entrevista com } \\
\text { pais e professores } \\
\text { com foco na } \\
\text { perspectiva em } \\
\text { relação à partici- } \\
\text { pação dos filhos/ } \\
\text { alunos na escola } \\
\text {-SSI:entrevista } \\
\text { com estudantes } \\
\text { com foco nas } \\
\text { oportunidades de } \\
\text { participação } \\
\text { Dados quantita- } \\
\text { tivos: } \\
\text { SFA através de } \\
\text { entrevistas com } \\
\text { professores }\end{array}$ & 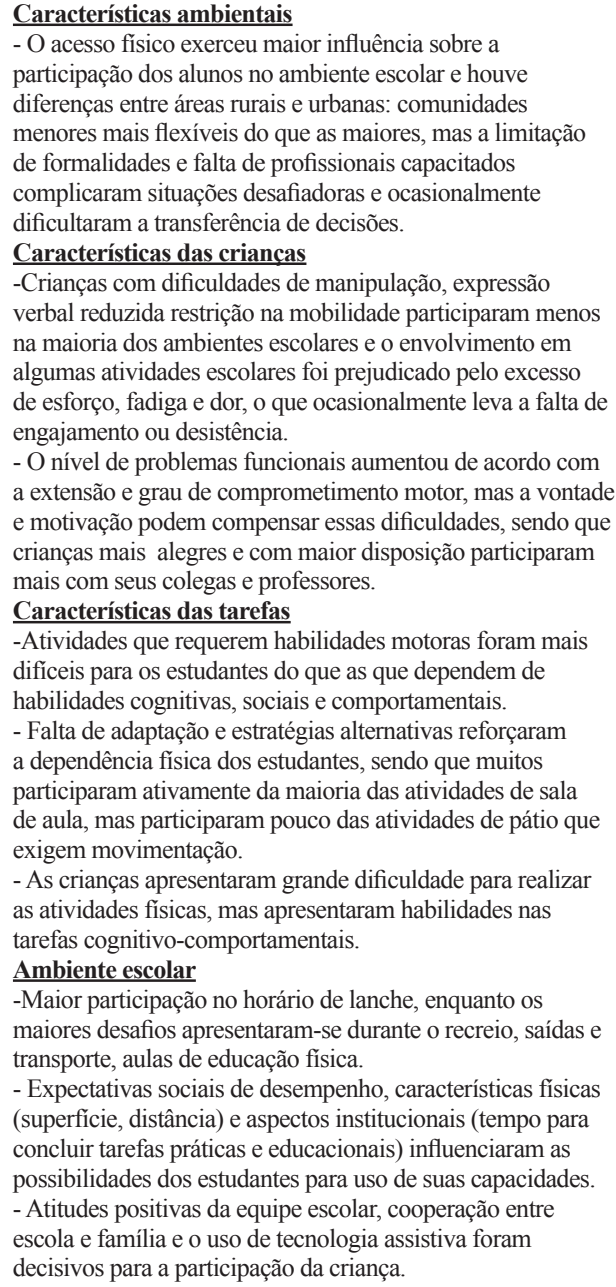 \\
\hline
\end{tabular}


GHEDINI, L. S. L. et al. Participação de alunos com deficiência. Rev. Ter. Ocup. Univ. São Paulo, v. 21, n. 1, p. 1-9, jan./abr. 2010.

\begin{tabular}{|c|c|c|c|c|}
\hline $\begin{array}{l}\text { VOOSLOO, S. M.. } \\
\text { The functioning of pri- } \\
\text { mary school learners with } \\
\text { paraplegia/paraparesis in } \\
\text { mainstream schools in the } \\
\text { Western Cape, South } \\
\text { Africa. An exploratory } \\
\text { study. } \\
\text { Disabil Rehabil, } \\
2009,31(1): 23-31 \text {. }\end{array}$ & $\begin{array}{l}\text { Explorar a realidade da } \\
\text { implementação de orien- } \\
\text { tações políticas para a } \\
\text { promoção da inclusão de } \\
\text { estudantes com paraple- } \\
\text { gia/ paraparesia na escola } \\
\text { regular primária }\end{array}$ & $\begin{array}{l}15 \text { estudantes } \\
\text { com paraplegia/ } \\
\text { paraparesia, de } 6 \\
\text { a } 14 \text { anos, e seus } \\
\text { respectivos pais e } \\
\text { professores }\end{array}$ & $\begin{array}{l}\text { Participação na } \\
\text { sociedade } \\
\text { (CHART ) } \\
\text {-Barreiras e } \\
\text { facilitadores para } \\
\text { a participação } \\
\text { na recreação, na } \\
\text { comunidade e na } \\
\text { escola } \\
\text { (CHIEF) }\end{array}$ & $\begin{array}{l}\text { - Obstáculos físicos, como escadas, diminuíram a } \\
\text { independência física dos cadeirantes. Quanto maior a } \\
\text { seriação escolar da criança, menor foi a sua mobilidade } \\
\text { entre os ambientes devido à necessidade de locomover-se } \\
\text { entre ambientes. } \\
\text { - No que se refere à independência cognitiva, os } \\
\text { estudantes necessitaram de assistência para cuidados e } \\
\text { tomadas de decisões. } \\
\text {-A maioria das crianças demonstrou bom equilíbrio entre } \\
\text { o tempo gasto com a família e com os amigos. } \\
\text {-Os estudantes despenderam muito tempo realizando } \\
\text { atividades produtivas na escola, porém, quando as } \\
\text { mesmas eram exercícios físicos, os estudantes evitavam } \\
\text { tais atividades, realizando atividades extras na sala de } \\
\text { aula ou terminando alguma atividade escolar inacabada. } \\
\text { Barreiras } \\
\text {-Problemas de acessibilidade e acomodação foram } \\
\text { considerados barreiras, sendo que a falta de adaptação } \\
\text { para realização de atividades físicas restringiu a } \\
\text { participação dos estudantes nestas atividades. } \\
\text { - Problemas maiores de acomodação identificados } \\
\text { incluíram acessibilidade devido a escadas, salas de aulas } \\
\text { localizadas em outros andares, passagens estreitas e falta } \\
\text { de acesso ao banheiro contribuíram para o baixo escore } \\
\text { de independência física. } \\
\text {-Inacessibilidade dos transportes públicos, condição } \\
\text { precária das ruas e a falta de rampas e inacessibilidades } \\
\text { dos meios-fios dificultaram o acesso à escola. } \\
\text { Facilitadores } \\
\text { - Recursos disponíveis, suporte social e igualdade foram } \\
\text { facilitadores de desempenho. Os recursos utilizados } \\
\text { consistiam em cadeira adaptada na sala de aula, } \\
\text { adaptação no computador e cuidadores facilitando o } \\
\text { acesso a diferentes ambientes. }\end{array}$ \\
\hline $\begin{array}{l}\text { HEMMINGSON, H.; } \\
\text { BORELL, L. Environmen- } \\
\text { tal barriers in } \\
\text { mainstream schools. } \\
\text { Child:Care Health Dev, } \\
\text { 2002;28(1):57-63. }\end{array}$ & $\begin{array}{l}\text { - Identificar as barreiras } \\
\text { ambientais presentes nas } \\
\text { escolas inclusivas, através } \\
\text { da perspectiva pessoal de } \\
\text { estudantes com defici- } \\
\text { ência física } \\
\text { - Investigar a relação } \\
\text { entre gênero, diagnóstico, } \\
\text { seriação, disponibilidade } \\
\text { de assistência, nível de } \\
\text { locomoção e ajustamento } \\
\text { aluno-ambiente }\end{array}$ & $\begin{array}{l}34 \text { estudantes com } \\
\text { deficiência física, } \\
\text { entre } 10 \text { e } 19 \text { anos } \\
\text { - Estudantes mais } \\
\text { jovens (EJ): abaixo } \\
\text { de } 13 \text { anos } \\
\text { - Estudantes mais } \\
\text { velhos } \\
\text { (EV): acima de } 13 \\
\text { anos }\end{array}$ & $\begin{array}{l}\text { Necessidade de } \\
\text { ajustes ambien- } \\
\text { tais na escola } \\
\text { para crianças } \\
\text { com } \\
\text { deficiência física } \\
\text { (SSI) }\end{array}$ & $\begin{array}{l}\text { - } 11 \text { estudantes relataram barreiras na acessibilidade, } \\
\text { devido à falta de rampas, elevadores e uso de diferentes } \\
\text { salas, e a maioria das barreiras físicas foi identificada } \\
\text { durante interações sociais. } \\
\text { - Estudantes que recebem assistência precisam de maior } \\
\text { ajuste ambiental na escola do que aqueles que não rece- } \\
\text { bem assistência. } \\
\text { - Estudantes mais velhos experimentam significativamen- } \\
\text { te mais barreiras do que os estudantes mais novos. } \\
\text { - Dificuldade da escola para atender as necessidades dos } \\
\text { estudantes mais velhos, relativas a ajustamentos ambien- } \\
\text { tais, uma vez que os estudantes mais velhos possuem } \\
\text { diferentes professores que utilizam diferentes salas. }\end{array}$ \\
\hline $\begin{array}{l}\text { HEMMINGSSON, H.; } \\
\text { BORELL, L.; } \\
\text { GUSTAVSSON, A. } \\
\text { Participation in school: } \\
\text { school sssistants } \\
\text { creating opportunities and } \\
\text { obstacles for } \\
\text { pupils with disabilities. } \\
\text { OTJR: Occup Particip } \\
\text { Health, 2003,23(3). }\end{array}$ & $\begin{array}{l}\text { - Explorar o tipo de } \\
\text { assistência oferecida aos } \\
\text { alunos com deficiência } \\
\text { física e a influência da } \\
\text { assistência na participação } \\
\text { na escola regular }\end{array}$ & $\begin{array}{l}-7 \text { alunos com } \\
\text { deficiência física, } \\
\text { com idade de } 7 \text { a } 15 \\
\text { anos: } 2 \text { inseridos } \\
\text { em sala especial e } 5 \\
\text { inclúdos em salas } \\
\text { regulares } \\
\text {-Respectivos } \\
\text { assistentes e } \\
\text { professores }\end{array}$ & $\begin{array}{l}\text { Observação } \\
\text { da assistência } \\
\text { oferecida aos } \\
\text { alunos com } \\
\text { deficiência física } \\
\text { e sua influência } \\
\text { na participação } \\
\text { (Entrevista semi } \\
\text { estruturada e } \\
\text { informais com } \\
\text { as crianças, } \\
\text { assistentes, pais e } \\
\text { professores) }\end{array}$ & $\begin{array}{l}\text { - A variação da posição da assistente na sala de aula tem } \\
\text { conseqüência importante no comportamento do aluno, e } \\
\text { pode ser classificada em } 3 \text { tipos:assistente a serviço do alu- } \\
\text { no; assistente auxiliar do professor e assistente ocasional, } \\
\text { que é aquele que auxilia o estudante apenas nas transferên- } \\
\text { cias e na locomoção, e que não permanece em sala de aula. } \\
\text {-Alunos com deficiência que receberam assistência não } \\
\text { tiveram a mesma oportunidade que os outros alunos para } \\
\text { tomarem decisões pessoais. } \\
\text {-A assistência parece reduzir a interação da criança com os } \\
\text { colegas e professores. } \\
\text {-Quando a assistência influenciou na participação social, a } \\
\text { criança com deficiência preferiu optar por não recebê-la. }\end{array}$ \\
\hline
\end{tabular}


GHEDINI, L. S. L. et al. Participação de alunos com deficiência. Rev. Ter. Ocup. Univ. São Paulo, v. 21, n. 1, p. 1-9, jan./abr. 2010.

\begin{tabular}{|c|c|c|c|c|}
\hline $\begin{array}{l}\text { LAW, M.; THERESA, P.; } \\
\text { GILLIAN, K.; PATRICIA, } \\
\text { H. } \\
\text { Perceived environmental } \\
\text { Barriers to Recreational, } \\
\text { Community, and School } \\
\text { Participation for Children } \\
\text { and Youth } \\
\text { With Physical Disabilities. } \\
\text { Arch Phys Med Rehabil, } \\
\text { 2007,188(12):1636- } \\
1642\end{array}$ & $\begin{array}{l}\text { - Descrever a percepção } \\
\text { de pais de crianças com } \\
\text { deficiência física sobre } \\
\text { barreiras ambientais na } \\
\text { participação de seus filhos } \\
\text { na recreação, comunidade } \\
\text { e escola. }\end{array}$ & $\begin{array}{l}427 \text { crianças com } \\
\text { deficiência física } \\
\text { em } 3 \text { idades : 6-8 } \\
\text { anos, } 9-11 \text { anos e } \\
\text { 12- } 14 \text { anos }\end{array}$ & $\begin{array}{l}\text { - Barreiras e } \\
\text { facilitadores para } \\
\text { a participação na } \\
\text { Recreação, na } \\
\text { comunidade e na } \\
\text { escola } \\
\text { (CHIEF) } \\
\text {-Habilidade da } \\
\text { criança para } \\
\text { desempenhar ati- } \\
\text { vidades de vida } \\
\text { diária (ASK) } \\
\text {-Comportamento } \\
\text { (SDQ) }\end{array}$ & $\begin{array}{l}\text { - O maior impacto das barreiras foi percebido pelos } \\
\text { pais como sendo na escola, ambiente de trabalho e em } \\
\text { ambientes naturais e construídos. } \\
\text {-Foi observada relação entre idade e impacto de barreiras } \\
\text { nos ambientes naturais e construídos, sendo que crianças } \\
\text { com idade entre } 12 \text { e } 14 \text { anos experimentaram impacto } \\
\text { significativamente superior ao que crianças com } 6 \text { a } 8 \\
\text { anos e } 9 \text { a } 10 \text { anos, nas áreas de serviço e assistência, } \\
\text { atitudes, escola e trabalho e política. } \\
\text {-Crianças com maior limitação no desempenho das ativi- } \\
\text { dades de vida diária demonstraram maior percepção das } \\
\text { barreiras em todas as áreas, exceto nas atitudes gerais. } \\
\text {-Crianças que apresentaram dificuldades comportamen- } \\
\text { tais significativas, obtiveram impacto significativamente } \\
\text { maior de barreiras de assistência e serviços. }\end{array}$ \\
\hline
\end{tabular}

*SFA: School Function Assessment; SSI: The School Setting Interview; CHART: The Craig Handicap Assessment and Reporting Technique; CHIEF: Craig Hospital Inventory of Environmental Factors ; ASK: Activity Scale for Kids; SDQ: Strengths and Difficulties Questionnaire.

\section{DISCUSSÃO}

Diante dos resultados apresentados pelos estudos, pode-se observar que os principais fatores que contribuem para a participação da criança com deficiência física na escola são a habilidade motora, especificamente seu repertório de mobilidade, a comunicação, o nível de comprometimento motor e a idade. Os alunos avaliados nos estudos apresentaram maior dificuldade para realizar tarefas que exigiam maior habilidade motora, como atividades de recreação no pátio/recreio, e quanto maior o comprometimento motor da criança, mais restrita foi sua participação. Os estudos também identificaram barreiras, como falta de acesso e inadequação do espaço físico das escolas, às necessidades das crianças com deficiência, que apresentaram limitação na participação, uma vez que sozinhos não conseguem transpor essas barreiras.

Dos oito artigos selecionados, quatro apontaram as habilidades motoras da criança como principal fator preditivo de participação de crianças com deficiência física, sendo observadas maiores dificuldades destes alunos para realizar tarefas físicas do que aquelas que exigiam habilidades cognitivas, repercutindo em participação mais restrita (SCHENKER et al., 2005, 2006; EGILSON; TRAUSTADOTTIR, 2009). Em estudo realizado por Silva et al. (2004), resultados indicaram que o grau de comprometimento motor foi um fator preditivo para o grau de participação. Mancini et al.
(2000) identificaram a capacidade física de crianças com deficiências variadas como possível fator preditivo para limitação na participação em escola de ensino regular, corroborando com os achados apresentados pelos demais estudos. Assim, observou-se relação importante entre habilidades motoras e participação da criança no contexto escolar. Crianças com limitação na mobilidade, segundo esses estudos, participaram de forma menos efetiva na maioria dos ambientes escolares, sendo que os problemas de acessibilidade e a falta de adaptações de atividades físicas foram citados como barreiras.

Dentre os artigos que consideraram as capacidades físicas da criança como importantes fatores para a participação escolar, dois estudos relataram que a participação dos alunos com deficiência física foi superior no contexto da merenda e inferior nas atividades de pátio/recreio (SCHENKER et al., 2005; EGILSON; TRAUSTADOTTIR, 2009). Egilson e Traustadottir (2009) enfatizaram que, embora a inclusão de estudantes com deficiência tenha sido defendida há anos, a construção e arquitetura das escolas ainda são planejadas considerando apenas os estudantes sem deficiência. Com isso, tornase necessário que assistência seja oferecida a essas crianças como forma de facilitar o acesso das mesmas aos diferentes ambientes escolares, prejudicado pelas barreiras físicas presentes. Alguns estudos constataram que o ambiente escolar torna-se mais acessível para crianças com deficiências incluídas em escolas regulares 
GHEDINI, L. S. L. et al. Participação de alunos com deficiência. Rev. Ter. Ocup. Univ. São Paulo, v. 21, n. 1, p. 1-9, jan./abr. 2010.

que recebem assistência do que para aquelas desprovidas de auxílio (HEMMINGSSON et al., 2002).

A relação entre a idade da criança e a participação também foi descrita em alguns artigos selecionados, sendo constatado que quanto maior a idade da criança mais restrita é a participação no ambiente escolar (VOSLOO, 2009; LAW et al., 2007; HEMMINGSON; BORELL, 2002) Hemmingsson e Borell (2002) e Law et al. (2007) justificaram que quanto maior a idade do estudante, maiores serão as adaptações ambientais necessárias, uma vez que com o aumento da seriação, os professores passam a utilizar diferentes salas, o que demanda maior deslocamento dos alunos e, no caso do aluno com deficiência física, será necessário maior auxílio para que o mesmo possa transpor essas barreiras. Law et al. (2007) argumentaram ainda que na transição para a adolescência, a criança procura expandir suas relações sociais e recreacionais, o que, para o aluno com deficiência, pode ser prejudicado pelas barreiras físicas presentes na escola. Nesses casos, observa-se a necessidade de construção de novas estratégias para que a escola possa adaptar sua dinâmica e seu espaço físico às dificuldades da criança com deficiência.

Dois artigos selecionados relataram que crianças com deficiência física que também apresentaram comprometimento na fala, participaram menos no ambiente escolar (SCHENKER et al., 2005; EGILSON; TRAUSTADOTTIR, 2009). Embora a linguagem verbal não seja a única forma de comunicação, quando o repertório verbal é inadequado ou limitado, ou seja, quando a fala não se manifesta adequadamente, ou, sobretudo, ininteligível, reduz-se consideravelmente a oportunidade de interação do indivíduo nos diversos ambientes sociais, como na escola (PAULA; ENUMO, 2007). Segundo Harper e Mccluskey (2002), crianças com limitações na fala tenderam a apresentar menor interação social com colegas do que crianças deficientes que apresentaram habilidades de linguagem superiores. Nesses casos, é importante que formas alternativas de comunicação sejam implementadas, como a comunicação alternativa, que trata-se de uma forma de desenvolvimento lingüístico, com o objetivo final de que as crianças sejam capazes de se comunicar com seus pares e com os adultos sobre os mesmos assuntos e nas mesmas situações que as crianças com fala/linguagem verbal (TETZCHNER, 2005).

É importante ressaltar que a participação escolar está relacionada às demandas de cada ambiente e que, embora os estudos apontem para uma relação direta entre comprometimento motor e participação, tal relação não deve ser compreendida como linear e unidirecional. Na verdade, é possível que, para crianças com deficiência física que apresentam maior comprometimento de repertório motor, esta relação apresente-se de forma mais evidente. Entretanto, crianças com menor comprometimento do repertório motor encontrarão outras demandas que podem influenciar a participação delas na escola. De fato, fatores do contexto tais como os valores culturais e as características dos ambientes físico, social, político nos quais a criança convive, bem como os fatores pessoais que a constituem como estudante, entre outros fatores, podem interferir na relação entre comprometimento motor e participação escolar, em crianças com comprometimentos leve e moderado. Para este subgrupo de estudantes com deficiência, as demandas escolares podem apresentarse como distintas e requerer deles competências que ultrapassam o repertório motor. A participação destas crianças poderá então estar mais relacionada à adequação do acesso, à disponibilidade de adaptações nas atividades e nos materiais escolares, entre outros, os quais podem variar de acordo com a escola (EGILSON; TRAUSTADOTTIR, 2009; VOSLOO, 2009; LAW et al. 2007; HEMMINGSON; BORELL, 2007). Entretanto, tal argumentação permanece como hipótese a ser testada empiricamente.

\section{CONCLUSÃO}

Pode-se observar que a relação entre habilidade motora e participação foi investigada em vários estudos selecionados para esta revisão, sendo que os mesmos apontaram que quanto maior for o comprometimento motor da criança, mais restrita poderá ser sua participação. Alguns artigos também identificaram como ambiente de menor participação desses alunos o pátio /recreio, e observaram maior participação no horário do lanche. Assim, observa-se que não somente as habilidades motoras estão envolvidas na participação da criança com deficiência física, mas também fatores relacionados às demandas das diferentes atividades e da acessibilidade física aos variados ambientes escolares, como pátio, sala de aula, banheiro, recreio. 
GHEDINI, L. S. L. et al. Participação de alunos com deficiência. Rev. Ter. Ocup. Univ. São Paulo, v. 21, n. 1, p. 1-9, jan./abr. 2010.

GHEDINI, L. S. L.; MANCINI, M. C.; BRANDÃO, M. de B. Participation of students with physical disabilities in mainstream schools- literature review. Rev. Ter. Ocup. Univ. São Paulo, v. 21, n. 1, p. 1-9, jan./abr. 2010.

\begin{abstract}
The inclusive education is a current reality, which is not only for socialization of children with disabilities, but also for the creation of opportunities to enable the participation in different school contexts. Therefore, it is essential to prepare professionals involved in this process so that the child may have the necessary and appropriate support. From this perspective, the objective of the study is to analyze, by means of a literature review, the evidence available about participation of children with physical disabilities in the context of regular school. Searches were performed in electronics databases and in educational journals. The key words used were: cerebral palsy or physical disabilities, school inclusion and school participation and the respective translated terms to portuguese. Eight articles were included in the study. The synthesis of the evidence showed that the main factors that contributed to the participation of children with physical disabilities in the school environment were motor skills, specifically mobility and communication, level of motor impairment and age. Barriers that restricted participation, such as lack of access and inadequate of physical space at schools were also identified.
\end{abstract}

KEY WORDS: Physical disabilities. School inclusion. School participation.

\title{
REFERÊNCIAS
}

COSTER, W. J.; DEENEY, T.; HALTIWANGER, J.; HALEY, S.M. School function assessment. San Antonio, TX: The Psychological Corporation/Therapy Skill Builders, 1998.

EGILSON, S. T.; COSTER, W.J. Scholl Function Assessment: performance of Iceland student with special needs. Scand. J. Occup. Ther., v. 11, n. 4, p. 163-170, 2004.

GOMES, C; BARBOSA, A. J. G. Inclusão escolar do portador de paralisia cerebral: atitudes de professores do ensino fundamental. Rev. Bras. Educ. Esp., v. 12, n. 1, p.85-100, 2006.

HARPER, L. V.; MCCLUSKEY, K. S. Caregiver and peer responses to children with language and motor disabilities in inclusive preschool programs. Early Childhood Res. Q., v. 17, n. 17p. 148-166, 2002.

HEMMINGSON, H.; BORELL, L. Environmental barriers in mainstream school. Child Care Health Develop., v. 28, n. 1, p. 57-63, 2002.

HEMMINGSSON, H.; BORELL, L.; GUSTAVSSON, A. Participation in school: school assistants

Creating opportunities and obstacles for pupils with disabilities. OTJR Occup. Part. Health, v. 23, n. 3, p. ??-??, 2003.

JURDI, A.P. S.; AMIRALIAN, M.L.T.M. A inclusão escolar de alunos com deficiência mental: uma proposta de intervenção do terapeuta ocupacional no cotidiano escolar. Estudos Psicol., Campinas, v. 23, n. 3, p. 191-202, 2006.

JURDI, A. P. BRUNELLO, M. I. B.; HONDA, M. Terapia ocupacional e propostas de intervenção na rede pública de ensino. Rev. Ter. Ocup. Univ. São Paulo, v. 15, n. 1, p.26-32, 2004.

LAW, M.; THERESA, P.; GILLIAN, K.; PATRICIA, H. Perceived environmental barriers to recreational, community, and school participation for children and youth with physical disabilities. Arch. Phys. Med. Rehabil., v. 88, n. 12, p. 1636-1642, 2007.

MANCINI, M. C.; COSTER, W. J.; TROMBLY, C. A.; HEEREN, T. C. Predicting primary school participation in children with disabilities. Arch. Phys. Med. Rehabil., v. 81, p. 339-347, 2000.

PELOSI, M. B. As contribuições da comunicação alternativa no processo de inclusão escolar de uma criança com disfunção neuromotora. In: MACEDO. E, C.; GONÇALVES, M. J.; CAPOVILlA, F. C.; SENNYEY, A. L. Tecnologia em (Re) habilitação cognitiva 2002: um novo olhar para avaliação e intervenção. São Paulo: Centro Universitário São Camilo, 2002. p. 303-312,

PERENBOOM, R. J. M.; CHORUS, A. M. J. Measuring participation according to the International Classification of 
GHEDINI, L. S. L. et al. Participação de alunos com deficiência. Rev. Ter. Ocup. Univ. São Paulo, v. 21, n. 1, p. 1-9, jan./abr. 2010.

Functioning, Disability and Health (ICF). Disabil. Rehabil., v. 25, n. 11-12, p. 577-587, 2003.

ROCHA, E. F. CASTIOGLIONI. M. C.; VIEIRA, R. C. A inclusão da criança com deficiência na escola comum: reflexões sobre o papel da Terapia Ocupacional. Rev. Ter. Ocup. Univ. São Paulo, v. 12 , n. $1 / 3$, p. $8-14,2001$.

ROSA, S. S. Brincar, conhecer e ensinar. 3a. ed. São Paulo: Editora Cortez, 1998.

SCHENKER, R.; COSTER, W. J.; PARUSH, S. Neuroimpairments, activity performance, and participation in children with cerebral palsy mainstreamed in elementary schools. Develop. Med. Child Neurol., v. 47, n .12 p. 808-814, 2005.

SCHENKER, R.; COSTER, W. J.; PARUSH, S. Participation and activity performance of students with cerebral palsy within the school environment. Disabil. Rehabil., v. 27, n. 10, p. 539552,2005 .

SCHENKER, R.; COSTER, W. J.; PARUSH, S. Personal assistance, adaptations and participation in students with cerebral palsy mainstreamed in elementary schools. Disabil. Rehabil., v. 28, n. 17, p.1061-1069, 2006.

SILVA, A. I. T.; SILVA, D. B. R.; AGNELLI, L. B.; HIGUCHI, M. A.; OLIVEIRA, M. C.; SILVA, P. C.; MANCINI, M. C.; VARELLA, R. B. C. Perfil funcional de crianças com paralisia cerebral na escola regular segundo tipo de escola e comprometimento motor. Temas Desenvolvimento, v. 13, n. 74, p. 5-13, 2004.

TETZCHNER,S.V.; BREKKE, K.M; SJ $\square$ THUN,B.; GRINDHEIM, E. Inclusão de crianças em educação pré-escolar regular utilizando comunicação suplementar e alternativa. Rev. Bras. Educ. Esp., v. 11, n .2, p. 151-184, 2005.

VOSLOO, S. M. The functioning of primary school learners wit Eh paraplegia/paraparesis in mainstream schools in theWestern Cape, South Africa. An exploratory study. Disabil. Rehabil., v. 31, n. 1, p. 23-31, 2009. 